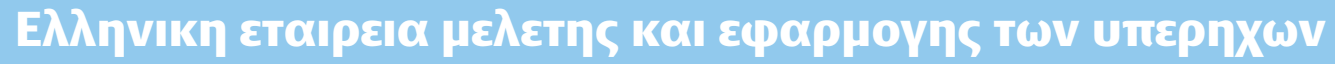

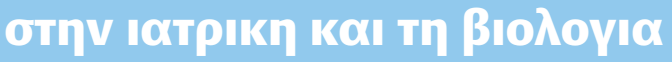
Hellenic Society of Ultrasound in Medicine and Biology

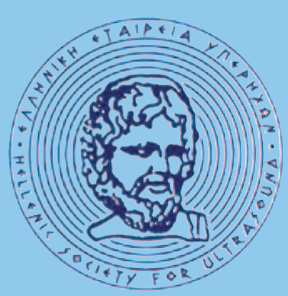

\title{
Athens, October 20th, 2021
}

The Hellenic Society for Ultrasound in Medicine and Biology (HSUMB) organized in collaboration with the $1^{\text {st }}$ Department of Obstetrics \& Gynecology, of University of Athens and the International Academy of Perinatal Medicine (IAPM) a Webinar on Fetal CNS evaluation and Fetal Neurology, on September 25th, 2021.

The Seminar was very successful with 560 registrations from 17 countries among which were Vietnam, Mexico, Brazil, Japan, Indonesia and other European countries. During the Seminar more than 250 fellows and doctors were constantly connected. The program was highly scientific and the speakers were scientists from Greece and abroad.

The success of the Seminar and the great participation will contribute to the ongoing organization of other similar Seminars of Ultrasound which will help our Doctors to be properly trained as well as to use the Diagnostic Ultrasound.

Best Regards

Aris Antsaklis MD, PhD, FRCOG (Hon.) Prof. of Obstetrics and Gynecology University of Athens Medical School President of Hellenic Society for Ultrasound in Medicine and Biology (HSUMB)

President of Mediterranean Society of Ultrasound in Obstetrics and Gynecology (MEDUOG)

Part President of World Association of Perinatal Medicine (WAPM)

Past President of European Association of Perinatal Medicine (EAPM)

Past Vice President of the International Academy of Perinatal Medicine (IAPM)

Director of the Greek Branch of Ian Donald School

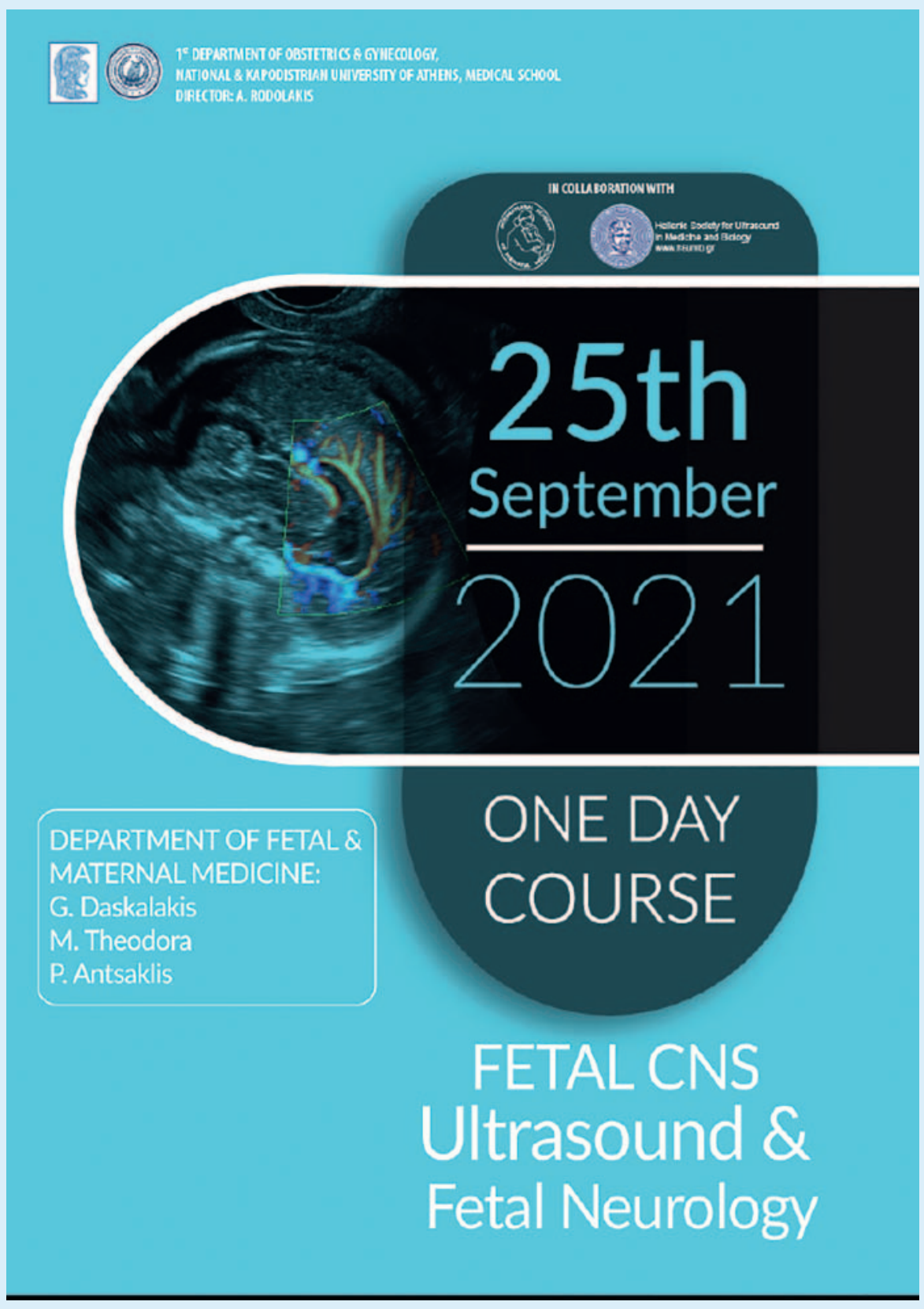

